\title{
commentary Questioning the efficacy of predatory journals' blacklists
}

\author{
Andrea Manca, Lucia Cugusi \& Franca Deriu (i) \\ COMMENTARY ON... PREDATORY JOURNALS AND DUBIOUS \\ PUBLISHERS ${ }^{\dagger}$
}

\begin{abstract}
Andrea Manca, MSc, $\mathrm{PhD}$, is a research fellow in physiology in the Department of Biomedical Sciences, University of Sassari, Italy. Lucia Cugusi, MSc, PhD, is a research fellow in cardiovascular sciences in the Department of Medical Sciences and Public Health, University of Cagliari, Italy. Franca Deriu, MD, $\mathrm{PhD}$, is Associate Professor of Physiology in the Department of Biomedical Sciences, University of Sassari, Italy.

Correspondence Franca Deriu, Human Physiology and Neurophysiology Laboratory, Viale S. Pietro 43/b, 07100 Sassari, Italy. Email: deriuf@uniss.it
\end{abstract}

First received 3 Nov 2018

Final revision 18 Nov 2018

Accepted 29 Nov 2018

\section{Copyright and usage}

(C) The Royal College of Psychiatrists 2019

${ }^{\dagger}$ See this issue.

\section{SUMMARY}

We question whether blacklists are the best answer to the serious problem of predatory journals. In conjunction with the worrying recent rise in the number of predatory journals, a remarkable number of blacklists have been compiled for specific scientific fields. However, predatory journals are continuously changing names and publishers; they are set up to make easy money and buried shortly after. Predatory journals have such a rapidly evolving nature that it is hard to keep track of them and keep blacklists up to date. We therefore propose a focus on 'whitelists' and directories of virtuous journals rather than on blacklists of pseudo-journals. We suggest that a set of criteria be determined that journals have to meet to be qualify as legitimate. In addition, the scientific community should come up with strategies to close the established biomedical databases to predatory journals, thus preventing them from achieving global exposure.

\section{DECLARATION OF INTEREST}

None.

\section{KEYWORDS}

Predatory journals; blacklists; whitelists; scholarly publishing; publication ethics.

Kisely's article (2018) is a comprehensive recognition of the predatory publishing phenomenon, reviewing the main characteristics of predatory journals and the tactics they use to target authors and make them prey. It is understood that predatory journals are a real threat to the credibility of science, so we welcome any attempt that scientists put in place to stand against them openly and efficiently. However, we question whether the 'blacklists of predatory journals' approach that Kisely endorses is the solution. If we look at the worrying data on the rise in the number of predatory journals since 2012 (Shen 2015; Shamseer 2017; Kisely 2018), we understand how hard it must have been for Professor Jeffrey Beall to keep his list of potential, possible, or probable predatory scholarly open-access publishers and journals up to date (https://beallslist.weebly.com). After reading his personal takes on predatory journals (Beall 2012, 2016), we felt so sympathetic with the work of this now-retired academic and librarian against the surge of predatory journals that we even dedicated passionate rhymes to his unrivalled commitment (Manca 2018a). We also engaged in tracking all the potential pseudo-journals active in our fields of research, resulting in the compilation of two blacklists (Manca 2017a, b). To our surprise, the methods described in those articles have been reprised by many authors, who drew up blacklists for various scientific fields (Cortegiani 2018; Rupp 2018; Shalom 2018).

\section{Replace blacklists with whitelists?}

Blacklists stemming from Beall's list serve the intended purpose of quantifying how many medical fields (and to what extent) have been affected by the phenomenon of predatory publishing. By doing so, discipline-specific blacklists have the potential to increase awareness among their respective scientific communities. However, in our experience, blacklists easily become outdated, even during the peer-review process of a submission. So, shortly after specific blacklists had begun to accumulate, we started wondering whether they were the most appropriate answer to the problem of predatory journals. What we have realised is that there are too many predatory journals to keep track of, so that maintaining up-to-date blacklists is a tough mission. Furthermore, predatory journals are continuously changing names and publishers. Fleets of them are set up to make fast money and then buried, only to be revived soon after in another guise. This is such a rapidly evolving (or devolving?) setting that it is hard to keep pace, even for predatory journals experts. 
So, how about focusing on how reputable, transparent and credible a journal should be rather than how disreputable it is? How about establishing a set of criteria on the basis of which a journal becomes eligible to qualify as legitimate? How about concentrating on 'whitelists' and directories of virtuous journals that meet those criteria? How about focusing on good rather than evil?

\section{But what about the grey zone?}

We have to admit, however, that the predatory journals problem can no longer be reduced to a simplistic black/white dichotomy. An increasing number of journals now operate in a 'grey zone', using a broad range of questionable tactics that are neither illegal nor easy to detect. This calls for a change of thinking about the concept of 'predatory publishing', which is very different today from a decade ago. This change should perhaps start with the terminology itself, as the term 'predatory journal' now belongs to a simpler past, as does Beall's blacklist. We now need another way of describing and tackling this evolving phenomenon.

\section{Protecting our databases}

As a final remark, how about doing our very best to make the established biomedical databases predator-free? As Kisely (2018) noted, this is a crucial issue that we raised in two recently published articles (Manca 2017c, 2018b) after discovering that a worrying number of predatory journals leak into PubMed via its free full-text repository, PubMed Central (PMC). If we can make all the relevant databases hermetically sealed to predatory journals, then these pseudo-journals will never achieve global exposure and will likely remain confined to the spam or trash folders of our email accounts which is exactly where they belong.

\section{References}

Beall J (2012) Predatory publishers are corrupting open access. Nature, 489: 179.

Beall J (2016) Predatory journals: ban predators from the scientific record. Nature, 534: 326

Cortegiani A, Longhini F, Sanfilippo F, et al (2018) Predatory open-access publishing in anesthesiology. Anesthesia \& Analgesia, 18 Sep: doi 10.1213/ANE.0000000000003803 [Epub ahead of print].

Kisely S (2018) Predatory journals and dubious publishers: how to avoid being their prey. BJPsych Advances, this issue.

Manca A, Martinez G, Cugusi L, et al (2017a) Predatory open access in rehabilitation. Archives of Physical Medicine and Rehabilitation, 98: $1051-6$

Manca A, Martinez G, Cugusi L, et al (2017b) The surge of predatory openaccess in neurosciences and neurology. Neuroscience, 353: 166-73.

Manca A, Cugusi L, Dvir Z, et al (2017c) PubMed should raise the bar for journal inclusion. Lancet, 390(10096): 734-5.

Manca A, Cugusi L, Deriu F (2018a) What to trust? What to ban? The wondering of a young scholar. Medical Teacher, 40: 1077-8.

Manca A, Moher D, Cugusi L, et al (2018b) How predatory journals leak into PubMed. CMAJ, 190: E1042-5.

Rupp M, Anastasopoulou L, Wintermeyer E, et al (2018) Predatory journals: a major threat in orthopaedic research. International Orthopaedics, 4 Oct: doi: 10.1007/s00264-018-4179-1 [Epub ahead of print].

Shalom G (2018) Predatory journals in dermatology: a hidden danger. Acta Dermato-Venereologica, 12 Sep: doi 10.2340/00015555-3038 [Epub ahead of print].

Shamseer L, Moher D, Maduekwe 0, et al (2017) Potential predatory and legitimate biomedical journals: can you tell the difference? A cross-sectional comparison. BMC Medicine, 15: 28.

Shen C, Björk BC (2015) 'Predatory' open access: a longitudinal study of article volumes and market characteristics. BMC Medicine, 13: 230. 